12,13

\title{
Исследование квазидвумерных и квазитрехмерных упорядоченных пористых структур методами малоугловой дифракции в скользящей геометрии
}

\author{
(С) И.С. Дубицкий ${ }^{1}$, Н.А. Григорьева ${ }^{2}$, А.А. Мистонов ${ }^{1,2}$, Г.А. Вальковский ${ }^{2}$, \\ Н.А. Саполетова ${ }^{3}$, С.В. Григорьев ${ }^{1,2}$ \\ ${ }^{1}$ НИЦ „Курчатовский институт“, \\ Петербургский институт ядерной фризики им. Б.П. Константинова, \\ Гатчина, Россия \\ ${ }^{2}$ Санкт-Петербургский государственный университет, \\ Санкт-Петербург, Россия \\ ${ }^{3}$ Московский государственный университет им. М.В. Ломоносова, \\ Москва, Россия \\ E-mail: ilya.dubitskiy@gmail.com \\ (Поступила в Редакцию 9 марта 2017 г. \\ В окончательной редакции 25 мая 2017 г.)
}

Метод малоуглового рассеяния синхротронного излучения в скользящей геометрии (GISAXS) впервые применен для исследования структуры приповерхностных слоев тонких металлических инвертированных опалов. На основании численной модели процесса рассеяния выделены вклады форм-фактора и структурного фактора в картину малоугловой дифракции. Взаимодополняющее использование SAXS- и GISAXS-методик позволило получить независимую информацию об объемных и поверхностных свойствах образцов, определить тип дефектов исследуемых структур. Результаты измерений были верифицированы с помощью атомносиловой микроскопии.

Работа была выполнена при финансовой поддержке РФФИ проектов 14-22-01113 офи_м и 16-32-00621 мол_а (И.С.Д. и А.А.М). А также при поддержке German-Russian Interdisciplinary Science Centre (проект P-2013b10).

DOI: $10.21883 /$ FTT.2017.12.45245.071

\section{1. Введение}

В последнее время активно исследуются метаматериалы, физические свойства которых в значительной степени определяются искусственно созданной периодической структурой составляющих их элементов [1,2]. Важным направлением исследований является изучение двумерных метаматериалов - метаповерхностей. В то же время быстрое развитие методов синтеза делает возможным создание трехмерно-упорядоченных наноструктур [3-7] - так называемых кластерных решеток. В частности, большой интерес представляют инвертированные опалоподобные структуры (ИОПС), состоящие из кластеров субмикронных размеров октаэдрической и тетраэдрической формы, соединенных друг с другом вершинами и образующих гранецентрированную кубическую (ГЦК) решетку. Такие структуры получают заполнением пустот между монодисперсными сферическими частицами полистирола или оксида кремния диаметром $D$ от $150 \mathrm{~nm}$ до $2.5 \mu \mathrm{m}$, образующими искусственные опалы (коллоидные кристаллы) [8-10]. Известно несколько способов заполнения пустот золь-гель метод [11], полимеризация [12], ионное распыление, импульсное лазерное напыление, электрохимическое осаждение [13], но только последний из них позволяет контролировать толщину (число монослоев) инвертированных опалов.

При осаждении материала-заполнителя на один слой гексагонально-упакованных сферических частиц можно получить двумерные (2M) ИОПС, которые после удаления сфер представляют собой разновидность пленочных структур с упорядоченными порами (antidot arrays). Периодичность пор определяется размером сферических частиц, а латеральный размер пор зависит от степени заполнения пустот слоя сферических частиц. Двумерные ИОПС проявляют необычные плазмонные [14-16,17-20], магнонные [21,22], магниторезистивные [23-25] и другие свойства.

При заполнении пустот нескольких слоев сферических частиц (коллоидного кристалла) получаются трехмерные (3М) ИОПС, наследующие не только физические свойства материала внедрения, но и характеризующиеся пространственной анизотропией проявления этих свойств. При этом последняя обусловлена выделенными кристаллографическими осями типа $\{111\}$, вдоль которых соединяются и последовательно чередуются тетраэдры и октаэдры [9,26,27]. Заполнение тетраэдрических и октаэдрических пустот оптически прозрачными полупроводниками [28] или сегнетоэлектриками [29] приводит к модификации фотонно-кристаллических свойств. 
В свою очередь, локализованные плазмонные резонансы наблюдаются в ИОПС на основе металлов [30,31], а заполнение опаловых пустот никелем или кобальтом приводит к созданию ферромагнитных ИОПС с распределением векторов локальной намагниченности, подчиняющемуся „правилу льда“ $[26,27,32-34]$.

Наиболее совершенные ГЦК-структуры искусственных опалов получают при осаждении сферических частиц из водной суспензии на вертикальную подложку методом формирования регулярной структуры в области мениска при испарении дисперсной среды. При этом на подложке слой за слоем растет пленка опала вдоль направления [111] (перпендикулярно подложке), достигая толщин порядка 40-50 монослоев плотноупакованных сфер. Таким образом, полученные пленки только условно можно назвать коллоидными кристаллами, так как в одном из трех направлений структура оказывается не бесконечной. А значит, при исследовании таких систем всегда следует учитывать изменения их физических свойств при переходе структуры из 2М- в 3М-измерение. Для изучения этих свойств необходимо разрабатывать соответствующие методики исследования и комплементарный подход в их применении.

Вопросы изменения физических свойств пленочных образцов опалоподобных структур при переходе из 2М- в 3М-измерение уже обсуждались нами в статьях [35-37] при анализе данных, полученных методами ультрамалоуглового рассеяния синхротронного излучения и SQUID-магнетометрии. В работах $[38,39]$ освещены теоретические и экспериментальные вопросы исследования двумерных и трехмерных опалоподобных фотонных структур с помощью оптических методов. Работа [40] посвящена оптическим исследованиям двумерных периодических структур различной симметрии. В статье [41] была сделана попытка по данным спектроскопии комбинационного рассеяния определить зависимость изменения фазового состава 2М- и $3 \mathrm{M}$-инвертированных опалоподобных структур на основе оксида ванадия с привлечением визуального контроля сканирующей микроскопии. Авторы [42] рассчитывали интенсивности дифракции света на искусственных опалах в зависимости от толщины образца (количества слоев сферических частиц). В работе [43] показано, что ИОПС на основе $\mathrm{Ni}$ с контролируемой топологией поверхности меняют свои оптические и тепловые свойства в зависимости от толщины образца (степени заполнения опаловой матрицы металлом), причем изменения выше названных свойств возможны только для образцов с идеальной 3М-структурой. Отметим, что полное понимание физических свойств тонких пленок ИОПС и корректная интерпретация экспериментальных данных возможны только при наличии детальной информации о структуре их объема и поверхности.

Настоящая статья посвящена разработке методов исследования объемных и поверхностных свойств пленок ИОПС, а именно - малоуглового рассеяния синхротронного излучения в обычной (SAXS) и скользящей
(GISAXS) геометриях падения луча на образец, и описанию комплементарного подхода их применения. Для верификации результатов интерпретации GISAXS-данных были проведены исследования поверхности образцов методом атомно-силовой микроскопии (АСM).

\section{2. Образцы и методика экспериментов}

2.1. Синтез образцов. ИОПС на основе кобальта и никеля были синтезированы темплатным методом [44]. В качестве шаблона (темплата) использовался коллоидный кристалл, состоящий из полистирольных микросфер диаметром порядка $542 \mathrm{~nm}$ для $\mathrm{Ni}$ ИОПС и порядка $618 \mathrm{~nm}$ для Со ИОПС. Микросферы были получены реакцией полимеризации стирола в присутствии персульфата калия как инициатора [45]. Распределение микросфер по размерам было исследовано с помощью сканирующей электронной микроскопии. Согласно статистической обработке микрофотографий величина стандартного отклонения составляет 14 и $17 \mathrm{~nm}$ для сфер, использованных для синтеза $\mathrm{Ni}$ и Со ИОПС соответственно. Таким образом, сферы характеризуются монодисперсностью по размерам не хуже $3 \%$.

Коллоидный кристалл формировался посредством вертикального осаждения микросфер из водной суспензии (рис. 1, $a$ ) на подложку монокристаллического кремния $[10]$ (рис. $1, b)$. Предварительно на подложку был нанесен слой золота толщиной $200 \mathrm{~nm}$.

Электрохимическое осаждение никеля и кобальта в пустоты между микросферами проводилось в трехэлектродной электрохимической ячейке в потенциостатическом режиме из раствора никель- или кобальтсодержащего электролита $[44,46]$ (рис. 1,c). В качестве катода использовался слой золота на кремниевой подложке, в качестве вспомогательного электрода - платиновая проволока. После заполнения пустот на определенную толщину полистирольные микросферы были растворены в толуоле (рис. $1, d)$.

Методом малоуглового рассеяния синхротронного излучения было показано, что коллоидные кристаллы [47] и инвертированные на их основе опалы $[10,33,48]$ имеют двойникованную ГЦК-структуру.

Техника электрохимического осаждения материалазаполнителя позволяет контролировать количество металла, поступившего в поры коллоидного кристалла, с помощью хроноамперограмм [44]. Считая, что первый монослой ИОПС заканчивает формирование, когда толщина металлического покрытия достигает диаметра микросфер $D$ (рис. $1, d)$, можно рассчитать расстояние $d$ - толщину последующих монослоев, $d \sqrt{2 / 3} D$. В данной работе представлены исследования пленок ИОПС на основе кобальта, имеющих толщины 0.5 и 2 монослоя, и ИОПС на основе никеля с толщинами 0.5 , 1 и 3.5 монослоя, площадь образцов порядка $1.5 \mathrm{~cm}^{2}$. GISAXS сигнал от более толстых образцов не наблюдался (см. раздел 3.2). Образцы толщиной 0.5, 1 

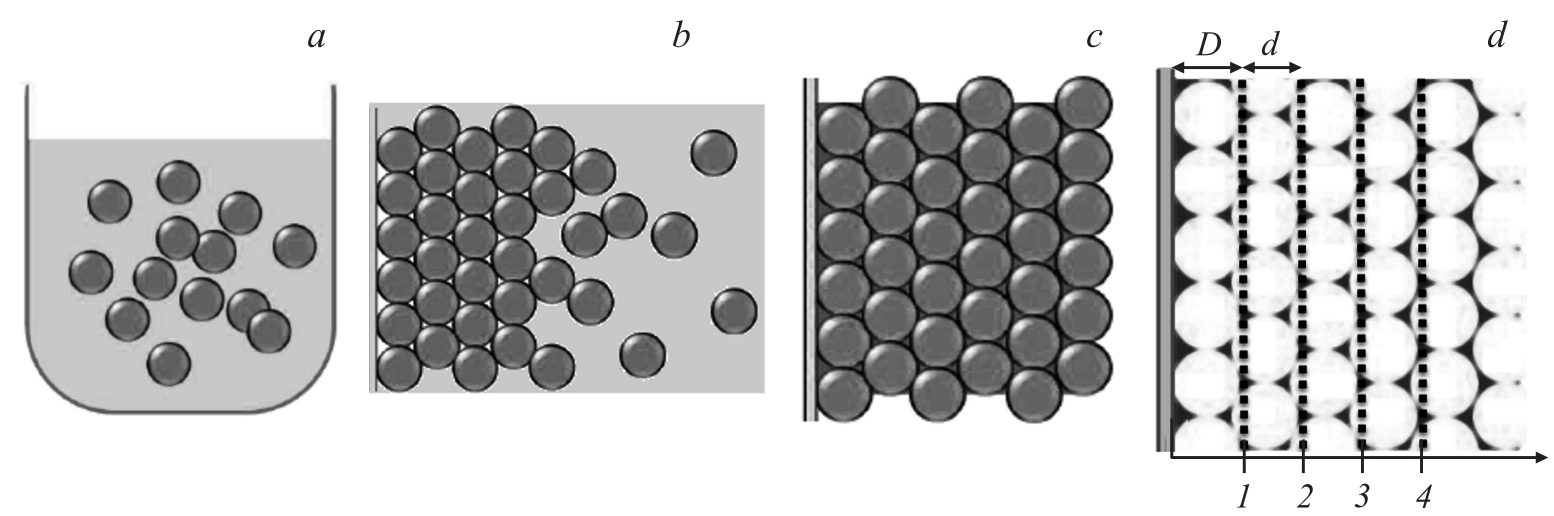

Рис. 1. Стадии синтеза инвертированного опала. (a) Водная суспензия полистирольных микросфер, $(b)$ осаждение микросфер на подложку, $(c)$ электрохимическое осаждение металла в пустоты между микросферами, $(d)$ растворение микросфер, цифрами отмечены первые четыре монослоя ИОПС.

и 2 монослоя мы будем называть квазидвумерными. Образцы толщиной 3.5 и более монослоев представляют собой квазитрехмерные системы, так как пленочные образцы искусственных опалов и ИОПС на их основе имеют малое число слоев в перпендикулярном направлении к подложке (до 40-50 слоев). Поэтому, хотя в образцах толщиной 3.5 монослоя и более уже сформирована элементарная ячейка ГЦК-структуры, они не обладают пространственной периодичностью во всех трех измерениях.

Изображения поверхности и скола квазитрехмерных ИОПС на основе никеля, полученные с помощью сканирующего электронного микроскопа (СЭМ), приведены на рис. 2. Стрелками отмечены основные кристаллографические направления в кластерной решетке ИОПС.

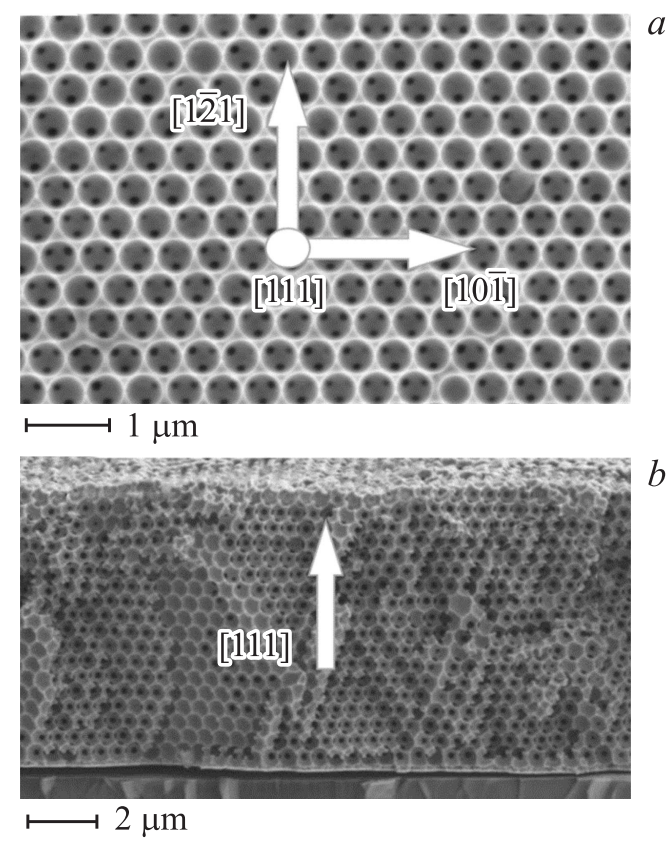

Рис. 2. СЭМ-изображение поверхности $(a)$ и скола $(b)$ ИОПС на основе никеля толщиной 17 монослоев.
2.2. Экспериме нтальные методики. Для ACМ-измерений был использован микроскоп Bruker Dimension Icon Технологического института Карлсруэ (KNMF Laboratory for Microscopy and Spectroscopy, Карлсруэ, Германия). Микроскоп работал в полуконтактном режиме снятия изображений (tapping mode).

АСМ-измерения позволяют сделать предварительные заключения о виде поверхности исследуемых образцов. Однако их статистическая значимость невелика, при том, что получение АСМ-изображений высокого разрешения требует существенных временных затрат.

Эксперименты по малоугловому рассеянию синхротронного излучения в скользящей (рис. 3,a) и обычной (рис. 3, $b$ ) геометриях проводились на станции DUBBLE BM26 Европейского центра синхротронных исследований (ESRF, Гренобль, Франция) [49]. Энергия падающего излучения составляла $13 \mathrm{keV}$, длина волны $\lambda=0.95 \AA$ с разрешением $\Delta \lambda / \lambda=10^{-4}$. Рассеянное излучение регистрировалось двумерным CCD детектором (VHR, Photonic Science), расположенном на расстоянии $6.5 \mathrm{~m}$ от образца. Размер пикселя детектора составлял $23 \times 23 \mu \mathrm{m}$. Система бериллиевых линз, установленных перед образцом для фокусировки пучка, позволила уменьшить его расходимость до 5 микрорадиан [50]. Аппаратное уширение дифракционных максимумов составило $4 \pi\left(5 \cdot 10^{-6} / 2\right) / 0.095=3.3 \cdot 10^{-4} \mathrm{~nm}$ что на порядок меньше их ширины. Площадь засветки образца синхротронным лучом достигала $2.5 \cdot 10^{-2} \mathrm{~mm}^{2}$ для SAXSгеометрии. В случае GISAXS-геометрии синхротронное излучение засвечивало всю поверхность образцов.

B GISAXS-экспериментах (рис. 3,a) синхротронное излучение с волновым вектором $\mathbf{k}$ падало на образец под малым скользящим углом $\alpha_{i} \approx 0.2^{\circ}$. Двумерный детектор регистрировал упруго $\left(\mathbf{k}_{i}=\mathbf{k}_{f}\right)$ рассеянное излучение $\mathbf{k}_{f}$ поверхностью образца вдоль направлений, определяемых углами $\alpha_{f}$ и $\theta_{f}$. Ось $O Z$ на рис. 3, $a$ направлена перпендикулярно поверхности образца (вдоль кристаллографического направления прямой решетки [111]). Отраженный от поверхности образ- 


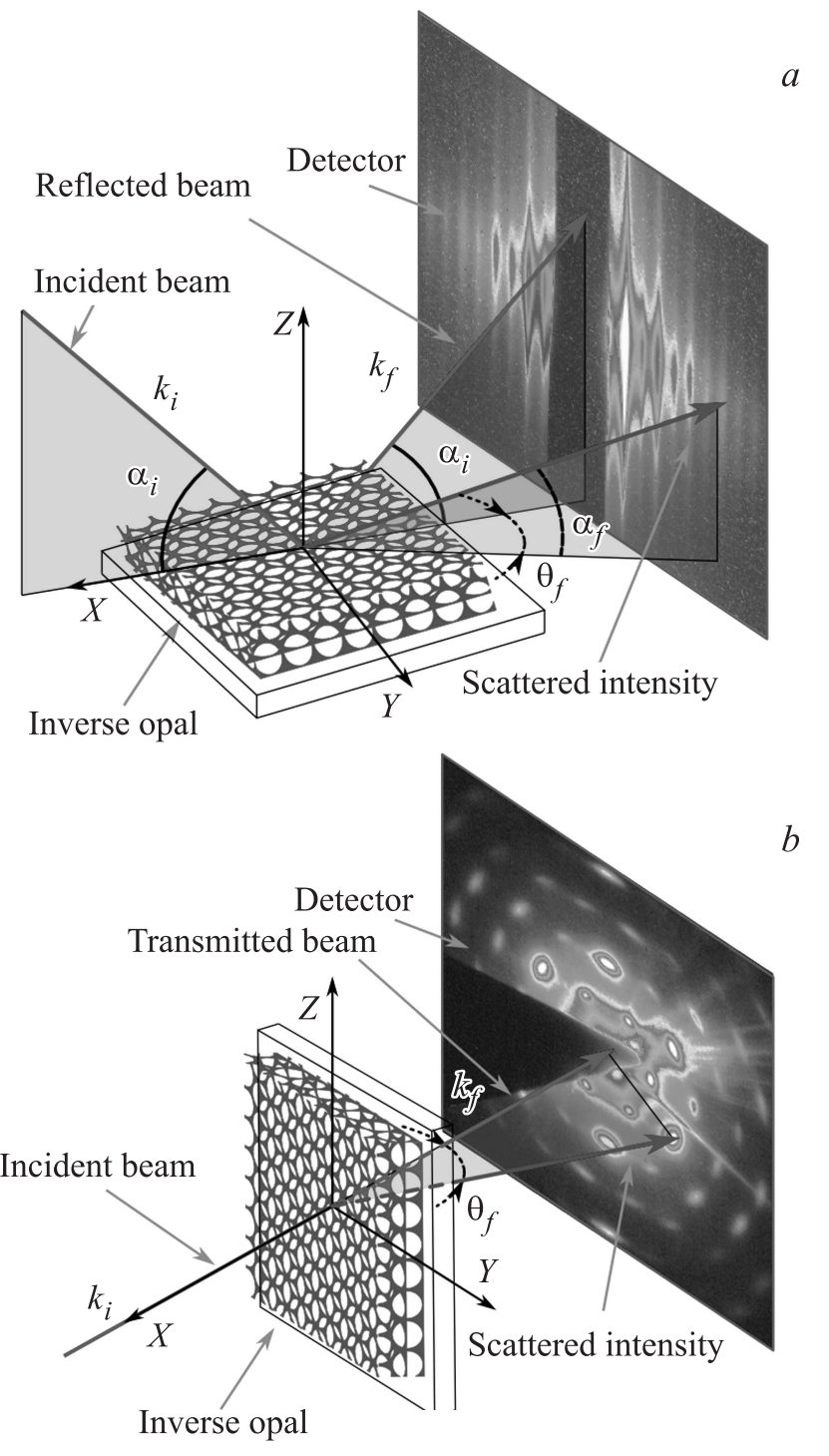

Рис. 3. Геометрия GISAXS $(a)$ и SAXS $(b)$ экспериментов.

ца пучок был закрыт поглотителем. В ходе GISAXSэкспериментов образец поворачивался вокруг $O Z$ на угол $\omega$. Значение $\omega=0^{\circ}$ соответствовало ориентации, при которой кристаллографическое направление прямой

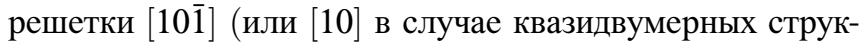
тур) ориентировано вдоль падающего пучка и перпендикулярно плоскости детектора.

SAXS-измерения квазидвумерных ИОПС проводились при перпендикулярном падении излучения на поверхность образца (вдоль оси $O Z$ на рис. 3,b). Для исследования объемного упорядочения квазитрехмерных инвертированных опалов был проведен ряд измерений при вращении образцов вокруг оси $O Y$.

Данные, полученные методом SAXS позволяют восстановить обратное пространство исследуемого объекта [51]. Если образец слабо поглощает излучение, и угол падения излучения на его поверхность в скользящей геометрии больше критического угла полного внешнего отражения, то и по данным метода GISAXS возможно восстановление обратного пространства [52]. Для сильно поглощающих образцов, когда метод GISAXS не подходит для восстановления обратного пространства, методы SAXS и GISAXS становятся взаимодополняющими для полноценной аттестации структуры объекта. Именно такой сценарий реализуется при исследовании металлических ИОПС.

\section{3. Результаты измерений и их обсуждение}

3.1. Атомно-силовая микроскопия. ACMизображения поверхности ИОПС на основе никеля и кобальта толщиной 0.5 монослоя приведены на рис. 4 и рис. 5 соответственно. При осаждении никеля и кобальта в поры кристалла-темплата первый кристаллизуется в ГЦК-структуру [32], второй — в ГПУ [33]. Наличие

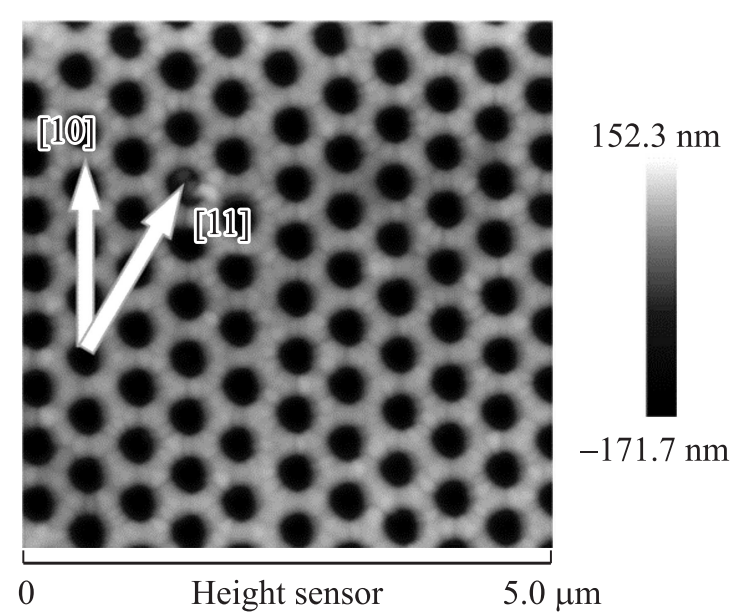

Рис. 4. АСМ-изображение поверхности ИОПС на основе никеля. Толщина 0.5 монослоя. Стрелками показаны основные направления прямой двумерной гексагональной кластерной решетки.

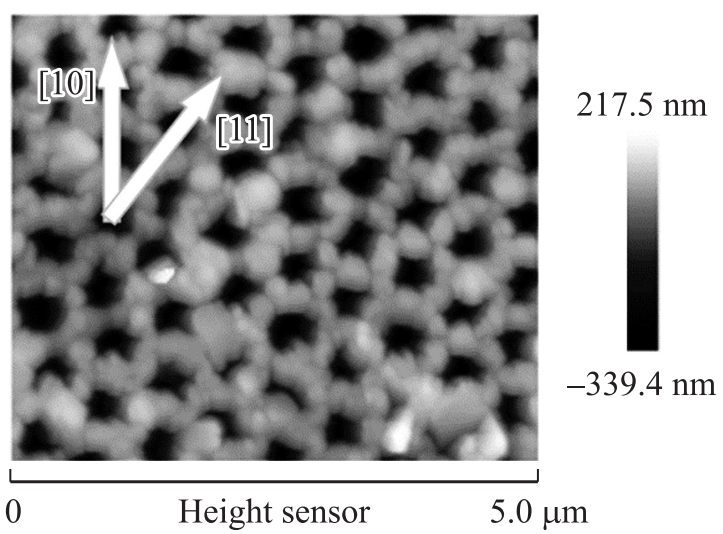

Рис. 5. АСМ-изображение поверхности ИОПС на основе кобальта. Толщина 0.5 монослоя. Стрелками показаны основные направления прямой двумерной гексагональной кластерной решетки. 

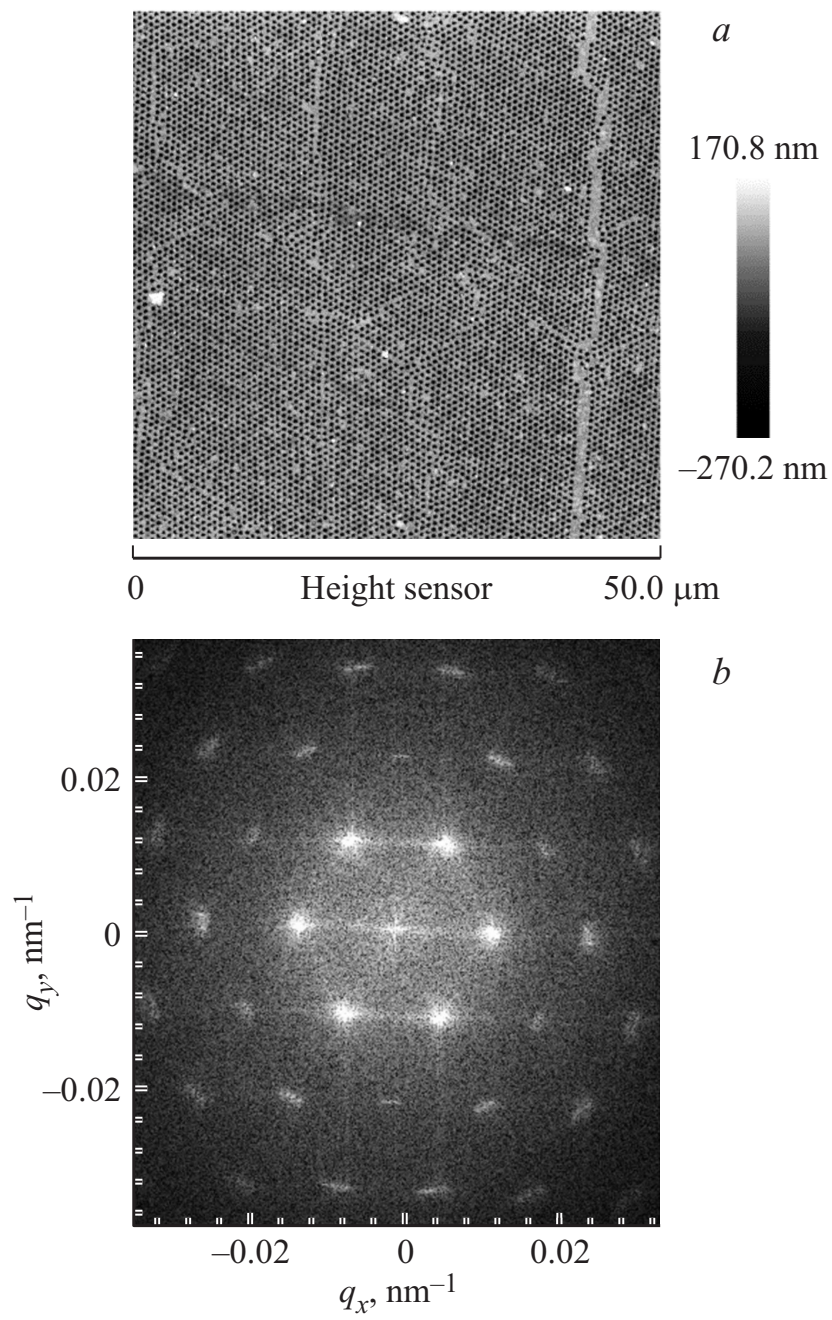

Рис. 6. АСМ-изображение ИОПС на основе кобальта толщиной 0.5 монослоя $(a)$ и его Фурье образ $(b)$.

выделенного направления роста для ГПУ-структуры при кристаллизации в порах оставляет меньше степеней свободы для поверхностной диффузии по сравнению с изотропным случаем. В результате в случае Со-ИОПС образуется более шероховатая пленка (рис. 5) по сравнению с ИОПС на основе никеля (рис. 4).

На основании анализа соотношения глубины полостей, образованных микросферами коллоидного кристалла, и ширины перемычек между ними (рис. 4) можно заключить, что толщина двумерных ИОПС превышает 0.5 монослоя. А именно, глубина полостей составляет около $440 \mathrm{~nm}$, что соответствует реальной толщине таких ИОПС порядка 0.9 монослоев. Данный анализ будет использован нами в разд. 3.2.1. Период структуры составил $490 \mathrm{~nm}$.

Анализ АСМ-изображений поверхности ИОПС проводился в обратном пространстве [53]. Типичный вид АСМ-изображения поверхности образца размером $50 \times 50 \mu \mathrm{m}^{2}$ и соответствующий Фурье образ приведены на рис. $6, a, b$ для ИОПС на основе кобаль- та. Наблюдаемые дифракционные максимумы соответствуют двумерной гексагональной решетке. Отсутствие колец указывает на однородность (структурную монодоменость) размером не менее $50 \times 50 \mu \mathrm{m}^{2}$ поверхности исследуемых образцов. Отметим, что если вся поверхность образца является однородной, то видимые в GISAXS-геометрии дифракционные максимумы должны быть эквидистантны, так как в данной геометрии на детекторе наблюдаются сечения обратного пространства плоскостями параллельными направлению $q_{z}$.

3.2. Малоугловое рассеяние синхротронного излучения в скользящей геометрии. Типичные картины рассеяния синхротронного излучения в скользящей геометрии, представляющие набор параллельных дифракционных полос, расположенных вдоль компоненты $q_{z}$ вектора рассеяния $\mathbf{q}=\mathbf{k}_{f}-\mathbf{k}_{i}$, для ИОПС на основе никеля толщиной 0.5 и 3.5 монослоя приведены на рис. 7.

Полосы не содержат каких-либо интерференционных максимумов в вертикальном направлении, что указывает на двумерный характер рассеяния. Кроме того, при углах скольжения меньших $1^{\circ}$ характерная длина затухания синхротронного излучения в никеле и кобальте не превосходит радиуса микросфер, из которых был изготовлен кристалл-темплат. Таким образом, можно заключить, что в GISAXS-эксперименте наблюдается дифракционная картина только от поверхности исследуемых образцов. Отражение синхротронного излучения наблюдалось только при рассеянии на образцах толщи-
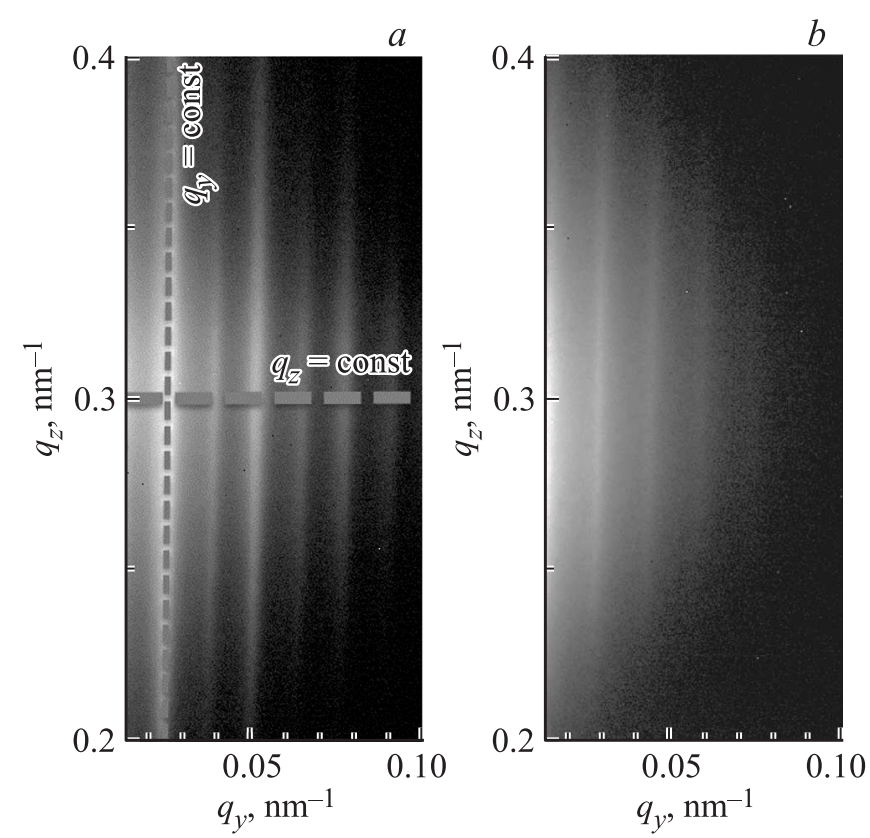

Рис. 7. Картина GISAXS-рассеяния на ИОПС на основе никеля толщиной 0.5 монослоя, угол поворота $\omega=30^{\circ}(a)$, толщиной 3.5 монослоя, угол поворота $\omega=0^{\circ}(b)$. Время экспозиции $600 \mathrm{~s}$. Показана половина дифракционной картины, расположенная справа от поглотителя прямого и зеркально отраженного пучков (рис. $3, a$ ). 


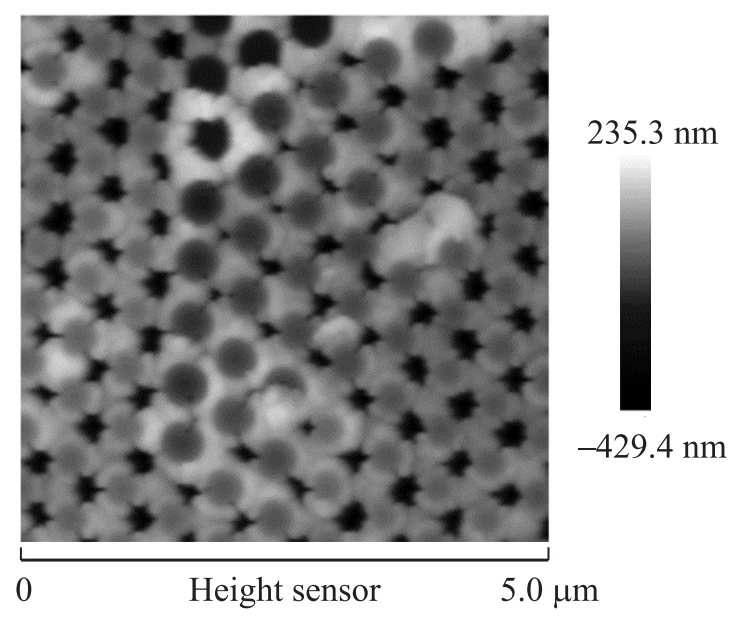

Рис. 8. АСМ-изображение поверхности Ni ИОПС толщиной 3.5 монослоя.

ной $\leq 3.5$ монослоев и только при углах скольжения меньших значения критического угла полного внешнего отражения. Критические углы для никеля и кобальта составляют $0.26^{\circ}$ при энергии падающего пучка равного $13 \mathrm{keV}$ [54].

Ослабление сигнала с ростом толщины образца (рис. 7) связано не только с поглощением излучения в металле, но и с ухудшением качества его поверхности (сравните АСМ-изображения поверхности $\mathrm{Ni}$ ИОПС толщиной 0.5 (рис. 4) и 3.5 (рис. 8) слоя).

3.2.1. Фор м - фак то р. Анализируя расположение дифракционных полос, наблюдаемых в GISAXS-эксперименте при различных углах $\omega$ вращения образца и используя дополнительные данные, полученные с помощью АСМ, можно восстановить вид поверхности ИОПС в обратном пространстве.

На основании АСМ-измерений (разд. 3.1) следует предположить, что поверхность ИОПС представляет собой монодоменную решетку. В этом случае дифракционные полосы должны располагаться эквидистантно. Однако в эксперименте (рис. 7) наблюдается набор промежуточных, более слабых по интенсивности максимумов. Особенно ярко они выражены для образца ИОПС на основе никеля толщиной 0.5 монослоя. На рис. 9, $a$ представлено распределение интенсивности рассеяния вдоль линии $q_{z}=$ const, соответствующей положению зеркально отраженного пучка для образцов ИОПС на основе никеля и кобальта толщиной 0.5 монослоя при угле поворота $\omega=30^{\circ}$ (кристаллографическое направление [11] кластерной решетки ИОПС совпадает с направлением падающего излучения).

Для выяснения природы происхождения данных промежуточных максимумов было проведено моделирование GISAXS-эксперимента в пакете ISGISAXS [55]. В простейшем случае интенсивность когерентного рассеяния $I(\mathbf{q})$ может быть представлена в виде произведения среднего значения квадрата модуля форм- фактора $\left\langle|F(\mathbf{q})|^{2}\right\rangle$ и структурного фактора $S(\mathbf{q})[56]$. В случае GISAXS-геометрии необходимо также принять во внимании динамические эффекты, а именно отражение и преломление падающего на образец излучения. Их можно учесть в рамках так называемого Борновского приближение искаженных волн (distorted wave Born approximation, DWBA) [57]. Пакет ISIGSAXS позволяет выполнять расчеты в этом приближении.

В качестве модели рассматривалась система гексагонально упорядоченных полостей в сплошном слое никеля. Полости имели форму усеченных сфер. На рис. 9, $b$ и рис. 10 представлены рассчитанная зависимость интенсивности рассеяния от величины переданного импульса $q$ и иезультат моделирования сечения обратного пространства ИОПС плоскостью $q_{z}$ соответственно. Широкие серые кольца на рис. 10 представляют максимумы форм-фактора от усеченных сфер, в то время как белые точки соответствуют структурному фактору

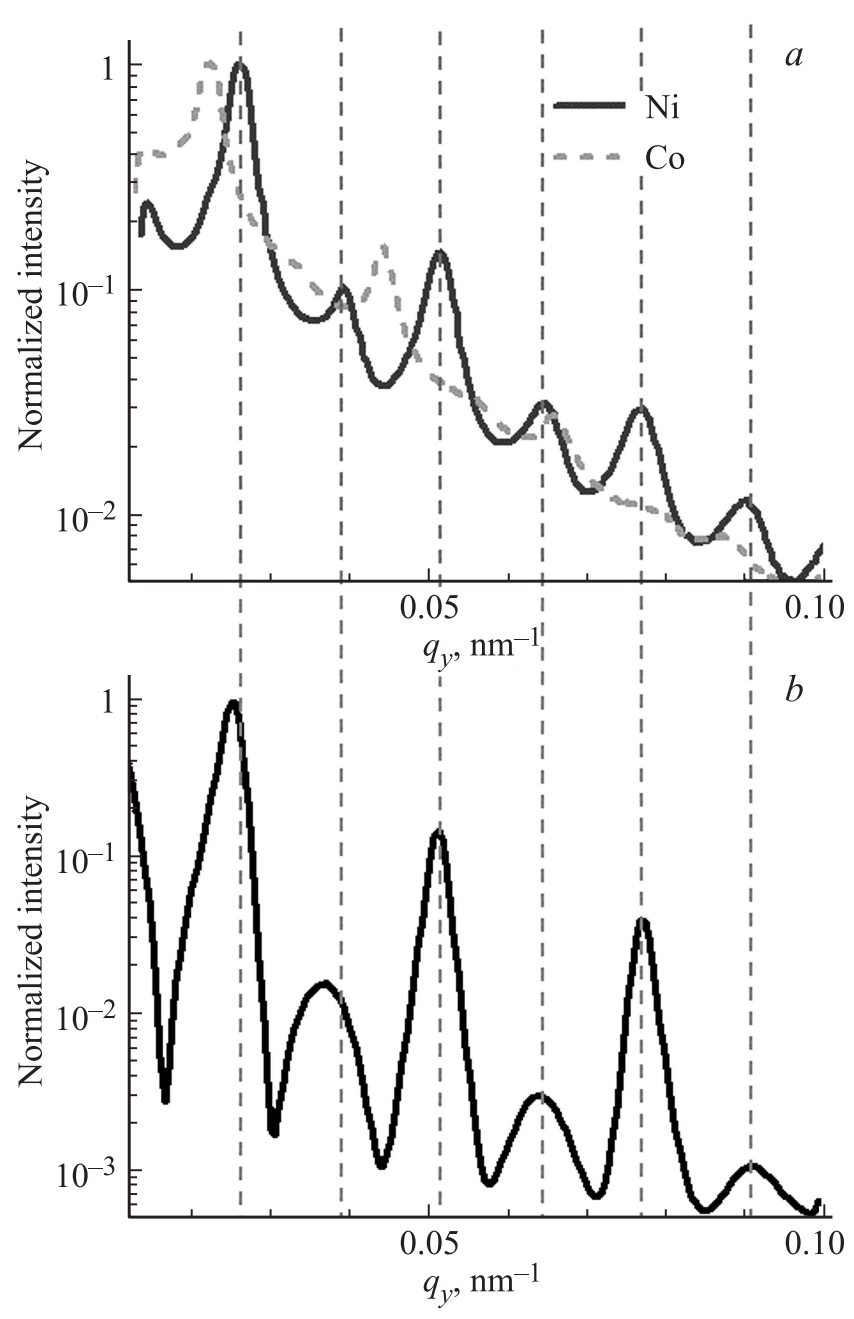

Рис. 9. (а) Зависимость интенсивности GISAXS-рассеяния от величины переданного импульса $q_{y}$ (вдоль линии $q_{z}=\mathrm{const}$ на рис. 7) для ИОПС на основе никеля и кобальта толщиной 0.5 монослоя, угол поворота образцов $\omega=30^{\circ}$ и (b) рассчитанная кривая (см. описание в тексте). 


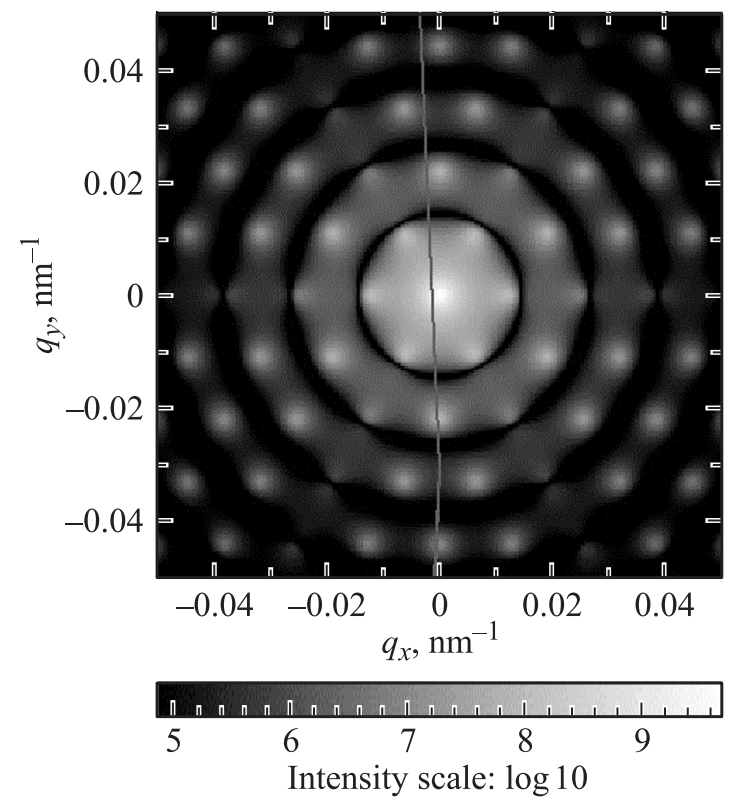

Рис. 10. Обратное пространство ИОПС (модель), след сферы Эвальда (вертикальная линия) соответствует углу поворота образца $\omega=30^{\circ}$.

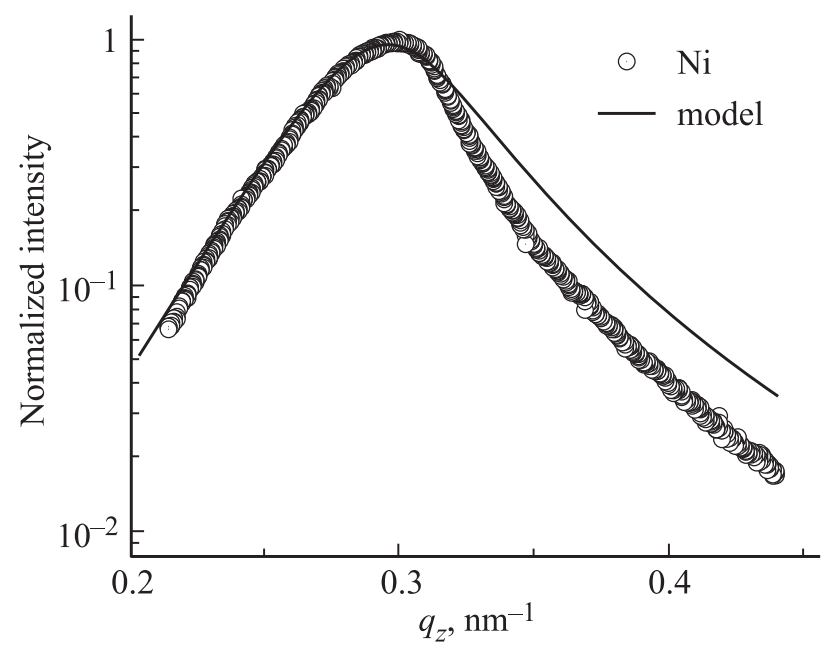

Рис. 11. Распределение интенсивности рассеяния вдоль первой дифракционной полосы (при фиксированном) для ИОПС на основе никеля толщиной 0.5 монослоя.

рассеяния на гексагонально-упорядоченных усеченных сферах. Рассчитанное сечение сферой Эвальда (вертикальная серая линия на рис. 10) обратного пространства (рис. 9, $b$ ) объясняет происхождение системы промежуточных максимумов на картине рассеяния (рис. 9, $a$ ).

Наилучшее согласие между расчетами и экспериментальными данными для ИОПС на основе никеля было достигнуто для периода решетки равного $490 \mathrm{~nm}$, радиуса сфер $235 \mathrm{~nm}$ и высоты сфер (глубины полостей) $430 \mathrm{~nm}$. Найденные период структуры и глубина полостей согласуются с результатами АСМ-измерений (490 и $440 \mathrm{~nm}$ соответственно). Отметим, что найденные периоды несколько меньше, чем размер полистирольных микросфер, с помощью которых был синтезирован прямой опал. Данное обстоятельство связано со сжатием микросфер при осаждении металла в полости темплата [58].

Распределение интенсивности вдоль дифракционных полос (линий $q_{y}=$ const на рис. $7, a$ ) также определяется видом форм-фактора.

На рис. 11 приведено распределение интенсивности рассеяния вдоль первой дифракционной полосы, полученное в эксперименте и в расчетах, для ИОПС на основе никеля толщиной 0.5 монослоя. Более быстрое убывание экспериментальной кривой может быть связано с недостаточной проникающей способностью синхротронного излучения вглубь образца вследствие сильного поглощения. Кроме того, известно, что полистирольные микросферы, образующие исходный коллоидный кристалл, могут быть подвержены небольшой $(\sim 2 \%)$ деформации (спеканию) [59]. Такая деформация также может привести к расхождению экспериментальных данных и расчета.

Расчеты показали, что для ИОПС на основе кобальта толщиной 0.5 монослоя, характеризующегося более сильной флуктуацией формы структурных (рассеивающих) элементов (рис. 5), влияние форм-фактора становится крайне слабым, и промежуточные максимумы (рис. 9, $a$ ) практически исчезают. Промежуточные максимумы также не наблюдаются с ростом толщины ИОПС, как на основе никеля, так и на основе кобальта, из-за их „размытия“ вследствие деградации качества поверхности (возрастания шероховатости).

3.2.2. С труктурный фактор. Для определения структурных свойств ИОПС с помощью метода GISAXS необходимо провести ряд измерений, поворачивая образец вокруг вертикальной оси на углы $\omega$ (ось $O Z$ на рис. $3, a)$. Как и ожидалось, дифракционная картина переходит сама в себя при вращении образца на угол $60^{\circ}$, что свидетельствует о наличии оси симметрии шестого порядка перпендикулярной плоскости образца. Также при повороте образца на углы 30, 90 и $150^{\circ}$ период чередования полос увеличивается в $\sqrt{3}$ раз по сравнению с $\omega=30^{\circ}$ (рис. 12).

На рис. 13 для ИОПС на основе кобальта толщиной 0.5 монослоя представлена зависимость периода чередования дифракционных полос вдоль $q_{z}=$ const, связанных со структурным фактором, от угла поворота образца. Сплошная линия соответствует модельным расчетам, проведенным в рамках предположения о гексагональной монодоменной структуре поверхности ИОПС. Таким образом, можно заключить, что поверхность ИОПС действительно представляет собой однородную, монодоменную гексагональную кластерную решетку.

При $\omega=0$ период чередования полос совпадает с вектором обратной решетки $a^{*}$. Учитывая соотношение $a a^{*}=4 \pi / \sqrt{3}$, можно найти период структуры $a$. Измеренный период ИОПС на основе никеля составил $490 \pm 10 \mathrm{~nm}$, ИОПС на основе кобаль- 


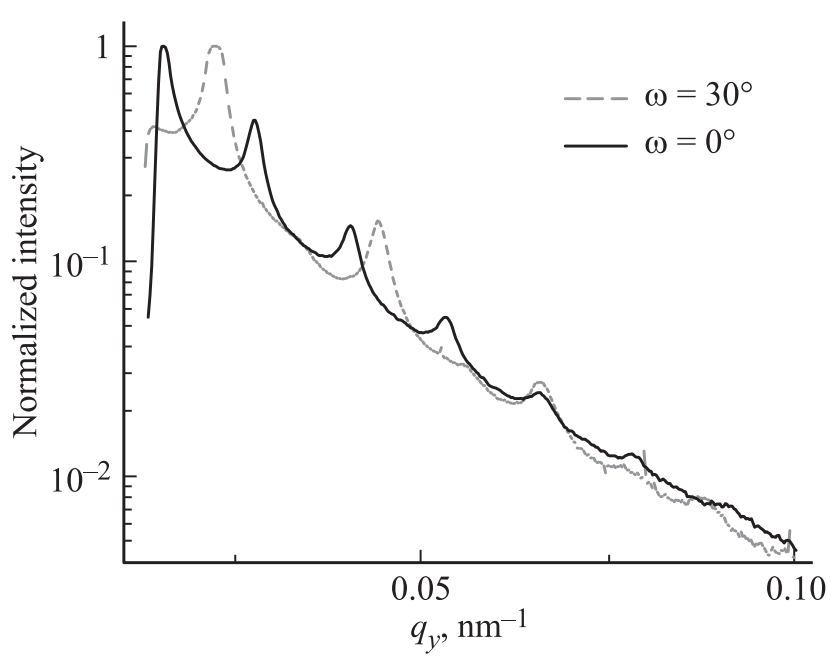

Рис. 12. Зависимость интенсивности GISAXS-рассеяния от величины переданного импульса $q_{y}$ для ИОПС на основе кобальта толщиной 0.5 монослоя при повороте образца на углы $\omega=0^{\circ}$ и $\omega=30^{\circ}$.

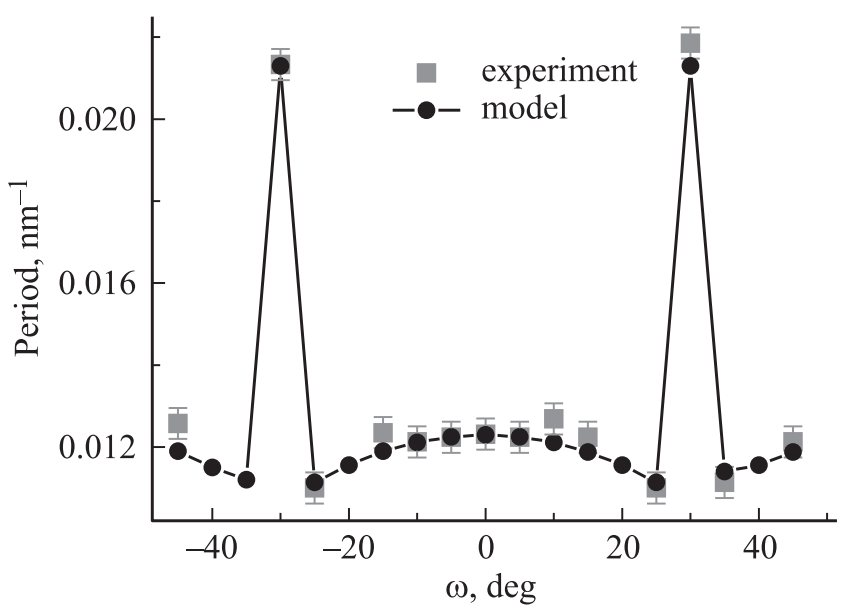

Рис. 13. Зависимость периода чередования полос от угла поворота образца ИОПС на основе кобальта толщиной 0.5 монослоя.

та $570 \pm 10 \mathrm{~nm}$. Различные значения периодов для $\mathrm{Ni}$ и Со ИОПС связаны с различным диаметром полистирольных микросфер, из которых были изготовлены исходные коллоидные матрицы. Полученные значения совпадают с результатами измерений АCM- и SAXS-методиками.

Заключение о монодоменности гексагональной кластерной решетки на поверхности тонких пленок инвертированных опалов по данным GISAXS позволяет проводить достоверные измерения методом магнитной силовой микроскопии (МСМ) для анализа распределения векторов локальной намагниченности. В работах $[27,60]$ было предсказано существование компоненты намагниченности перпендикулярной ферромагнитной пленке ИОПС при включении внешнего магнитного поля в плоскости пленки и изменение направления этой компо- ненты на противоположное при изменении направления внешнего магнитного поля на противоположное первоначальному. Наличие перпендикулярной компоненты намагниченности в пленке толщиной до 20-25 $\mu \mathrm{m}$ явление не ординарное и может иметь различные применения в микроэлектронике, однако на сегодняшний день нет ни одной экспериментальной методики, которая позволила бы это подтвердить или опровергнуть за исключением МСM.

Принимая во внимание, что данные МСМ исследований могут корректно интерпретироваться только на структурно монодоменных участках гексагональной кластерной решетки, следует точно определять границы таких участков путем исследования возможных дефектов поверхности ИОПС.

3.2.3. Де фекты пов ерхности. Поперечное уширение дифракционных полос связано с „не идеальностью“ структуры поверхности образцов ИОПС. Характерный размер $L$ области когерентного рассеяния можно найти из полной ширины максимумов на половине высоты $\Delta$. Для всех исследованных образцов она составляет $L=2 \pi / \Delta \approx 6 \pm 1 \mu \mathrm{m}$ или около 10 периодов гексагональной кластерной решетки. Аналогичные результаты были получены и с помощью анализа Фурье образов АСМ-изображений поверхности.

Обычно под $L$ подразумевают характерный размер структурных доменов, на которые разбивается образец. Однако анализ АСМ-изображений и результаты GISAXS-экспериментов показывают отсутствие доменов размера $L$ (рис. 6). С другой стороны, длину можно рассматривать как корреляционную длину, характеризующую согласованность флуктуаций формфакторов. В этом случае величина $L$ описывает быстроту убывания корреляционной функции форм-факторов $y_{m}$, определяемой в узлах решетки следующим образом: $y_{m} \equiv \overline{F_{n} R_{n+m}^{*}}$, где $F_{i}-$ форм-фактор $i$-го структурного элемента, $n$ и $m$ - мультииндексы, обозначающие пару целых чисел, связанных с данным узлом средней решетки (здесь используется терминология, введенная Гинье [61]). Усреднение производится по всему образцу.

Отметим, что величина корреляционной длины $L$ для образцов с гладкой (рис. 4) и шероховатой (рис. 5) поверхностями оказывается одинаковой в пределах погрешности измерений. Отсюда можно заключить, что корреляционная длина связана главным образом со смещением структурных элементов относительно их положения в идеальной решетке, но не с корреляциями формы структурных элементов. То есть корреляционная длина определяется строением исходного коллоидного кристалла, а процесс инвертирования не вносит дополнительных дефектов в структуру образцов.

Вид корреляционной функции может быть установлен с помощью анализа формы поперечного сечения дифракционных полос (рис. 7). На рис. 14 приведен результат аппроксимации экспериментальной кривой с помощью распределения Лоренца. Лоренцевой форме 


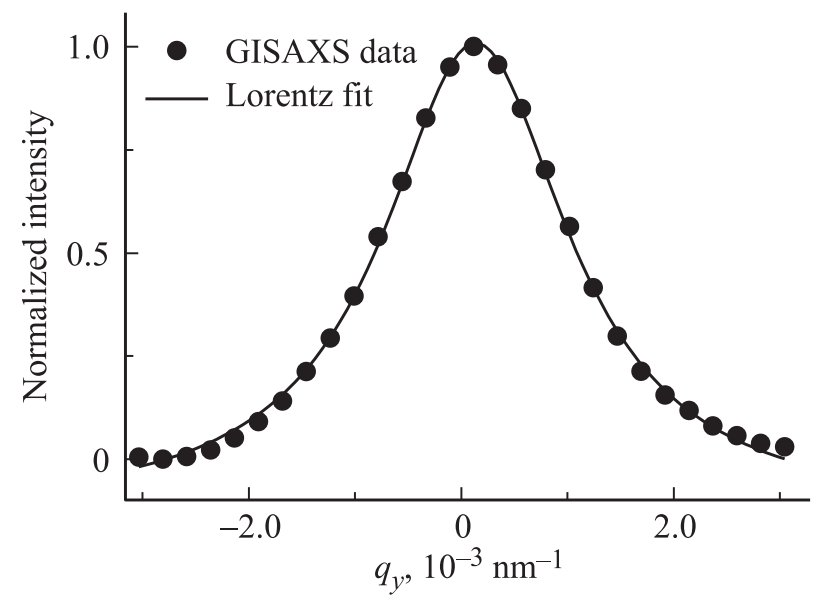

Рис. 14. Распределение интенсивности в поперечном сечении дифракционной полосы (вдоль линии $q_{z}=$ const) для ИОПС на основе кобальта толщиной 0.5 монослоя и аппроксимация его формы распределением Лоренца.

пиков соответствует экспоненциальный вид корреляционной функции [42].

В заключение следует сказать, что независимо от физической интерпретации длины $L$ размер области сканирования при проведении МСМ-экспериментов должен быть не меньше $L$ для обеспечения воспроизводимости результатов.

3.2.4. Шероховатость поверхности. В разд. 3.2.1 было показано, что при рассеянии на ИОПС с достаточно гладкой поверхностью форм-фактор сферических полостей вносит существенный вклад в дифракционную картину. Однако при возрастании шероховатости поверхности образцов промежуточные максимумы, связанные с данным форм-фактором, практически исчезают (сравните кривые для Ni- и Со- ИОПС на рис. 9, a). Изменяется также вид распределения интенсивности вдоль дифракционных полос (сравните рис. 11 и рис. $15, a)$. Такое распределение интенсивности можно использовать для оценки величины шероховатости.

Определим шероховатость как отклонение высоты поверхности пленки ИОПС относительно какого-либо среднего значения. Предположим, что отклонение высоты поверхности от среднего значения описывается распределением Гаусса $\propto \exp \left(-z^{2} / 2 \sigma^{2}\right)$, где $\sigma-$ среднеквадратичная высота шероховатости. Тогда, выполнив преобразование Фурье от данного распределения, мы получим следующее выражение для величины квадрата модуля форм-фактора $\left|F\left(q_{z}\right)\right|^{2} \propto \exp \left(-\left(q_{z}-q_{r z}\right)^{2} \sigma^{2}\right)$, где $q_{r z}$ соответствует центру отраженного пучка (GISAXS геометрия, рис. 3,a). Данная функция хорошо описывает распределение интенсивности вдоль дифракционных полос для всех Со ИОПС и для $\mathrm{Ni}$ ИОПС, толщина которых превышает 0.5 монослоя. В качестве примера на рис. 15, a приведены полученное в эксперименте распределение интенсивности вдоль первой дифракционной полосы, для ИОПС на основе кобальта толщиной 2 монослоя и его аппроксимация функцией Гаусса. Найденное с помощью аппроксимации значение $\sigma$ составило $40 \mathrm{~nm}$.

Среднеквадратичную шероховатость можно определить также методом АCM, анализируя распределение высоты поверхности пленки относительно среднего значения (рис. $15, b)$. Наличие узких и глубоких полостей на поверхности ИОПС (рис. 16) приводит к отличию экспериментально измеренной кривой от распределения Гаусса. GISAXS-рассеяние, в свою очередь, происходит в основном на самом верхнем слое металла, толщиной в несколько десятков $\mathrm{nm}$ вследствие сильного поглощения излучения. Шероховатость данного слоя и представляет основной интерес, так как может привести к появлению значительных шумов в МСМ-сигнале. Величины $\sigma$, найденные с помощью анализа АСМ-данных, согласу-

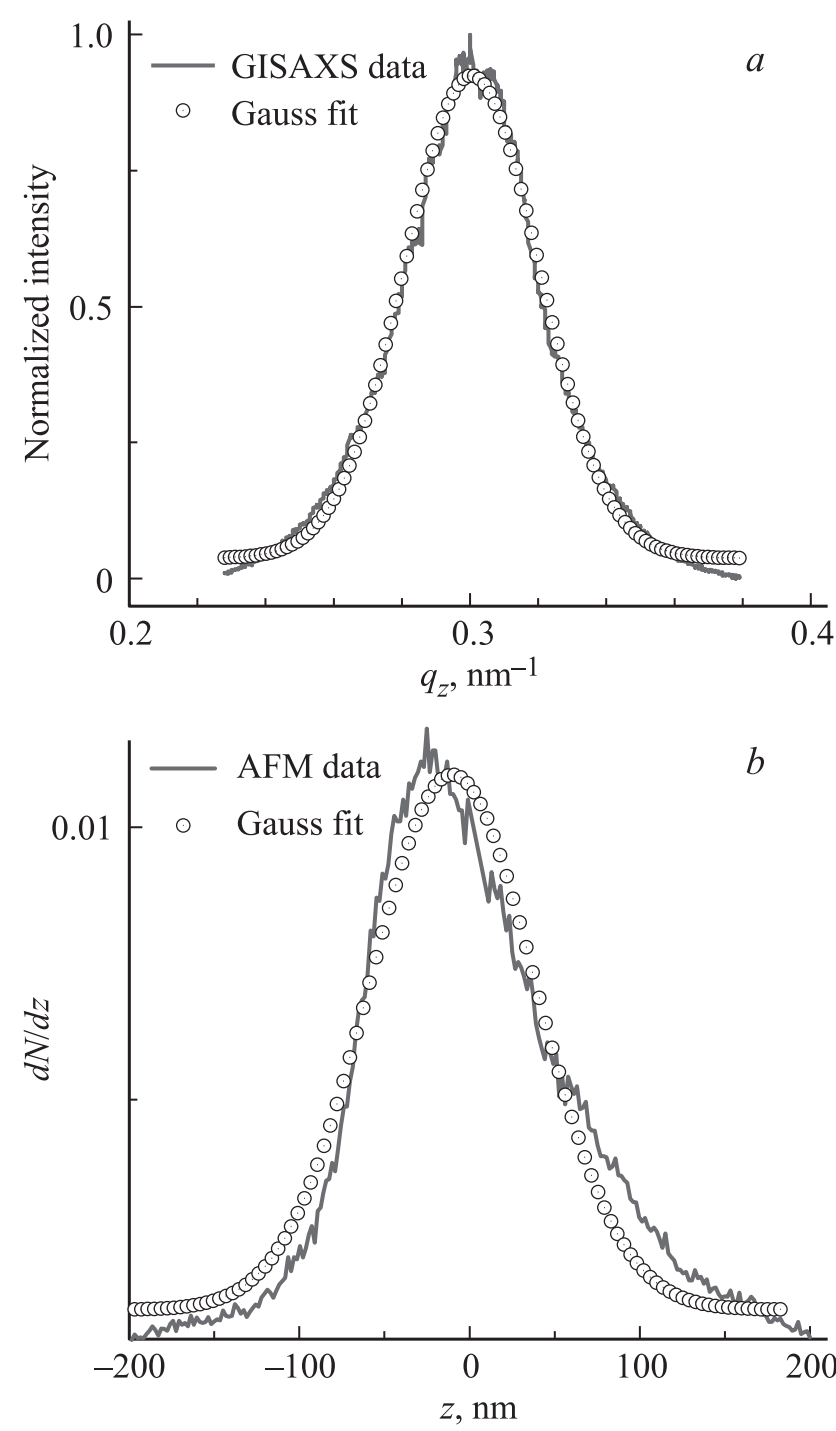

Рис. 15. (a) Распределение интенсивности вдоль первой дифракционной полосы для ИОПС на основе кобальта толщиной 2 монослоя и аппроксимация формы кривой функцией Гаусса, $(b)$ распределение высоты поверхности, полученное с помощью АCM, и его аппроксимация функцией Гаусса. 


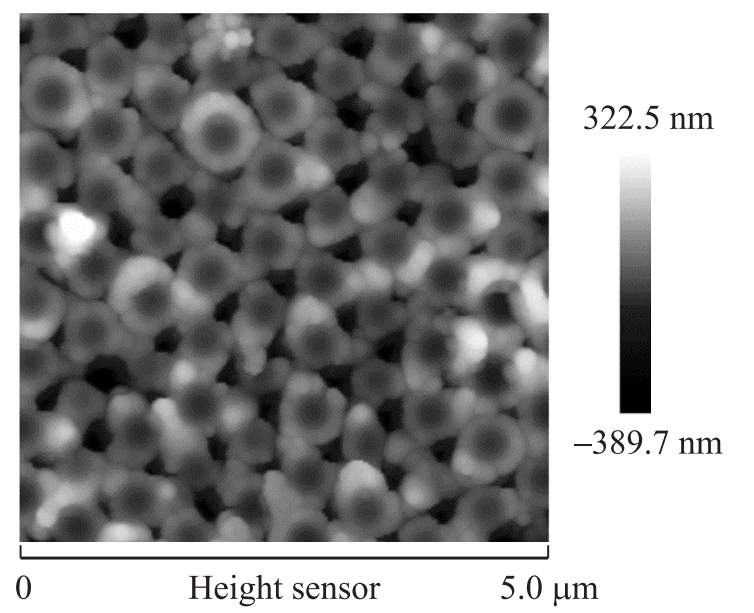

Рис. 16. АСМ-изображение поверхности ИОПС на основе кобальта толщиной 2 монослоя.

ются с результатами GISAXS-экспериментов. Отметим, что метод GISAXS позволяет проводить измерения шероховатости поверхности образцов большой площади (вплоть до нескольких $\mathrm{cm}^{2}$ ).

С ростом толщины образцов шероховатость возрастает. Так для ИОПС на основе кобальта толщиной 0.5 и 2 монослоя $\sigma$ составляет соответственно $25 \mathrm{~nm}$ и $40 \mathrm{~nm}$. В случае ИОПС, выполненных из никеля, шероховатость равна 20 и $30 \mathrm{~nm}$ для образцов толщиной соответственно 1 и 3.5 монослоя. Таким образом, величина шероховатости поверхности $\mathrm{Ni}$ - ИОПС меньше шероховатости Со- ИОПС аналогичной толщины, как и следовало ожидать (см. разд. 3.1).

3.3. Малоугловое рассеяние синхротронного излучения в SAXS геометрии. При исследовании структурных особенностей 2М- и $3 \mathrm{M}$ кластерных решеток, синтезированных последовательным наращиванием однотипных слоев, корректную интерпретацию результатов, полученных с помощью поверхностно-чувствительных методик (GISAXS, ACM, электронная микроскопия), следует дополнять методиками изучения объемной структуры (малоугловое рассеяние или малоугловая дифракция нейтронов и синхротронного излучения). В случае металлических ИОПС информацию об объемном упорядочении можно получить методом SAXS.

На рис. 17 приведены двумерные карты малоуглового рассеяния синхротронного излучения для образцов Со ИОПС толщиной 0.5 и $\mathrm{Ni}$ ИОПС толщиной 3.5 монослоя. Паразитное диффузное рассеяние в правой верхней части изображения связано с рассеянием излучения на поглотителе прямого пучка. Наблюдаемая дифракционная картина соответствует сечению обратного пространства плоскостью $q_{z}=0$ и находится в полном количественном согласии с Фурье образом АСМ-изображения (разд. 3.1) и данными GISAXS-измерений (разд. 3.2) в случае ИОПС толщиной 0.5 монослоя.
C ростом толщины образца начинают проявляться эффекты, связанные с интерференцией излучения между слоями (рис. 17, $b$ ). Анализ малоугловых карт рассеяния, полученных при вращении образца вокруг вертикальной оси $O Y$ (рис. $3, b)$, показал, что ИОПС толщиной от 3.5 слоев и более имеют ГЦК-структуру с плоскостью двойникования (111). Наличие на картине дифракции низкоинтенсивных максимумов характерных для гексагональной плотной упаковки (отмечены квадратом на рис. $15, b)$ связано с малыми толщинами исследуемых инвертированных опалов $[37,48]$.

Корреляционные длины $L$, характеризующие размер структурных доменов, полученные методами SAXS и GISAXS совпадают для каждого исследованного образца. Однако периоды кластерных решеток, измеренные с
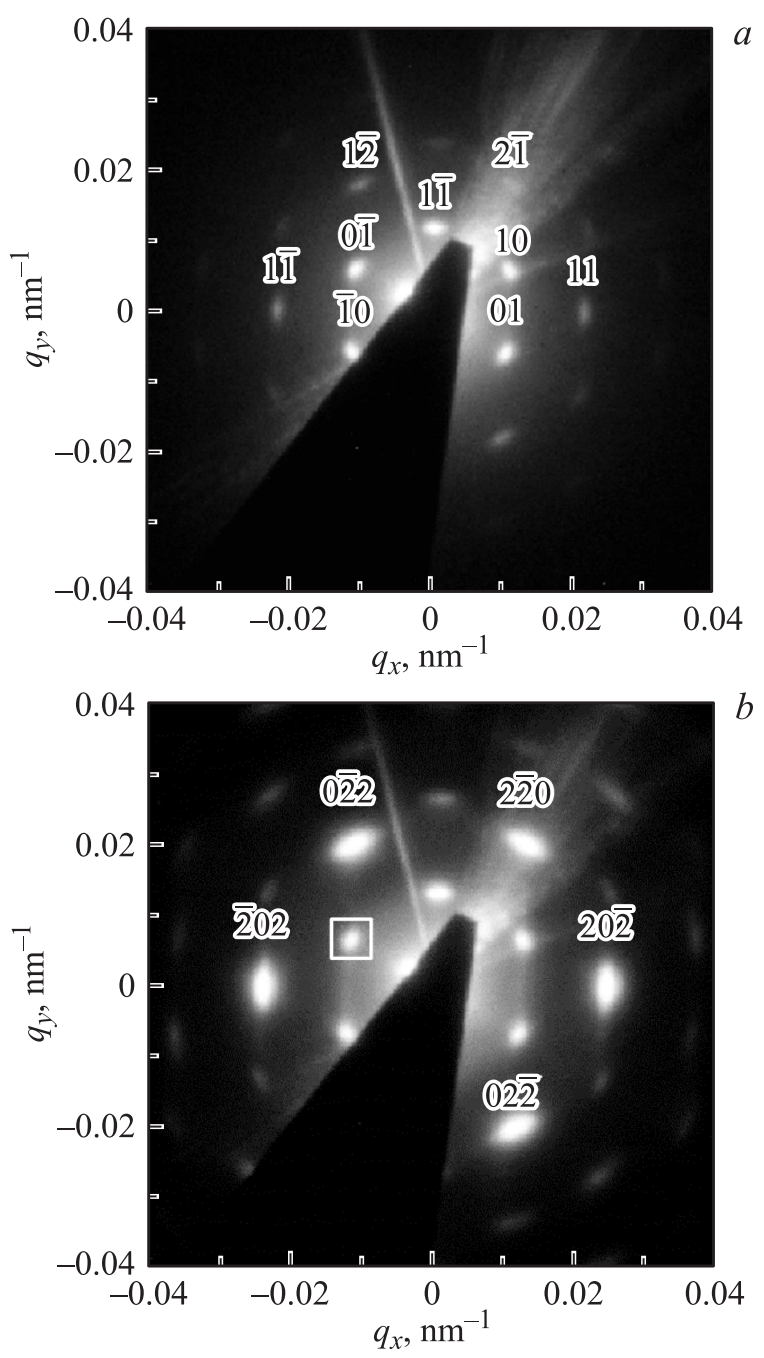

Рис. 17. Двумерные карты малоуглового рассеяния синхротронного излучения для образцов Со ИОПС толщиной $0.5(a)$ и Ni ИОПС толщиной $3.5(b)$ монослоя. Падающий пучок перпендикулярен поверхности образца (плоскость (111)). Цифрами отмечены основные дифракционные максимумы двумерной гексагональной решетки $(a)$ и ГЦК-решетки $(b)$. Квадратом отмечен один из рефлексов, запрещенных для ГЦК-структуры. Время экспозиции $10 \mathrm{~s}$. 
Результаты измерений периодов кластерных решеток методами SAXS GISAXS

\begin{tabular}{l|c|c}
\hline Образец & $\begin{array}{c}\text { Период } \\
\text { кластерной решетки } \\
\text { (метод GISAXS), (nm) }\end{array}$ & $\begin{array}{c}\text { Период } \\
\text { кластерной решетки } \\
\text { (метод SAXS), (nm) }\end{array}$ \\
\hline Co_0.5 & 571 & 576 \\
Co_2 & 560 & 577 \\
Ni_3.5 & 489 & 521
\end{tabular}

помощью метода SAXS, оказываются несколько больше периодов, найденных методом GISAXS - на 5, 17 и $32 \mathrm{~nm}$ для ИОПС толщиной $0.5,2$ и 3.5 монослоя соответственно (см. таблицу). В случае образцов толщиной 0.5 монослоя различие периодов не превосходит погрешности измерений, что указывает на корректность процедуры интерпретации данных. Расхождение для более толстых образцов объясняется небольшой деформацией внешних слоев ИОПС по сравнению с внутренними. Величина деформации не превышает $5 \%$.

\section{4. Заключение}

Методика рассеяния синхротронного излучения в скользящей геометрии (GISAXS) была впервые использована для исследования тонких пленок инвертированных опалов на основе никеля и кобальта. B GISAXS-экспериментах наблюдалась дифракционная картина рассеяния только от приповерхностных слоев исследуемых образцов из-за сильного поглощения рентгеновского излучения никелем и кобальтом. Расшифровка картин GISAXS-рассеяния на ИОПС проводилась на основе численного моделирования в пакете IS-GISAXS в рамках Борновского приближения искаженных волн. Установлено, что поверхность квазидвумерных и квазитрехмерных ИОПС представляет собой гексагональную монодоменную кластерную решетку, определен характерный размер области когерентного рассеяния для всех исследованных образцов $L=2 \pi / \Delta \approx 6 \pm 1 \mu \mathrm{m}$, что составляет 10 периодов гексагональной кластерной решетки. Показано, что процесс инвертирования не вносит дополнительных дефектов в структуру образцов. Найденные структурные параметры ИОПС на основе никеля и кобальта - периоды кластерных решеток, форм-факторы, шероховатость поверхности и размеры рассеивающих объектов, формирующих кластеры, удовлетворительно согласуются с данными атомно-силовой микроскопии, использованной для верификации результатов GISAXS-измерений.

Взаимодополняющее использование методов SAXS и GISAXS позволило независимо исследовать объемное и поверхностное упорядочение инвертированных опалов. Было установлено, что с ростом толщины ИОПС наблюдается небольшая деформация поверхности относительно объема, однако ее величина не превышает 5\%.
Установлено, что для проведения достоверных исследований магнитного состояния ИОПС в рамках поверхностно-чувствительных методик (например, МСМ) подходят тонкие (не более 3.5 монослоев) образцы $\mathrm{Ni-ИОПС.} \mathrm{При} \mathrm{этом} \mathrm{достаточно} \mathrm{исследовать} \mathrm{область} \mathrm{об-}$ разца размером порядка $6 \mu \mathrm{m}$ вследствие однородности его поверхности.

Представленная методика исследования объемного и поверхностного упорядочения многослойных структур может быть применена и к другим многослойным системам или кластерным решеткам.

Авторы благодарят персонал линии DUBBLE (ESRF) за гостеприимство, а также сотрудников Междисциплинарного ресурсного центра СПбГУ по направлению „Нанотехнологии“, Ресурсного центра „Физические методы исследования поверхности“"и KNMF Laboratory for Microscopy and Spectroscopy (Karlsruhe) за предоставленную возможность проведения СЭМ- и АCMизмерений.

\section{Список литературы}

[1] S. John. Phys. Rev. Lett. bf58, 2486 (1987).

[2] H. Engheta, R.W. Ziolkowski. Metamaterials: Physics and engineering explorations. Wiley-IEEE Press (2006). $440 \mathrm{c}$.

[3] C. Zhu, D. Du, A. Eychmuller, Y. Lin. Chem. Rev. 115, 8896 (2015).

[4] N.C. Lindquist, P. Nagpal, K.M. McPeak, D.J. Norris, S.H. Oh. Rep. Prog. Phys. 75, 036501 (2012).

[5] H. Hsueh, C. Yao, R. Ho. Chem. Soc. Rev. 44, 1974 (2015).

[6] A.A. Zhukov, A.V. Goncharov, P.A.J. de Groot. Appl. Phys. Lett. 88, 62511 (2006).

[7] V.A. Ukleev, N.A. Grigoryeva, E.A. Dyadkina, A.A. Vorobiev, D. Lott, L.V. Lutsev, A.I. Stognij, N.N. Novitskiy, A.A. Mistonov, D. Menzel, S.V. Grigoriev. Phys. Rev. B 86, 134424 (2012).

[8] А.И. Плеханов, Д.В. Калинин, В.В. Сердобинцева. Рос. нанотехнологии 1, 245 (2006).

[9] В.Н. Богомолов, Т.М. Павлова. ФТП 29, 826 (1995).

[10] K.S. Napolskii, N.A. Sapoletova, D.F. Gorozhankin, A.A. Eliseev, D.Y. Chernyshov, D.V. Byelov, N.A. Grigoryeva, A.A. Mistonov, W.G. Bouwman, K.O. Kvashnina, A.V. Lukashin, A.A. Snigirev, A.V. Vassilieva, S.V. Grigoriev, A.V. Petukhov. Langmuir 26, 2346 (2010).

[11] C.F. Blanford, T.N. Do, B.T. Holland, A. Stein, Mater. Res. Soc. Symp. Proc. 549, 61 (1999).

[12] S.A. Johnson, P.J. Ollivier, T.E. Mallouk. Science 283, 963 (1999).

[13] Q. Luo, Z. Liu, L. Li, S. Xie, J. Kong, D. Zhao. Adv. Mater. 13, 286 (2001).

[14] W.B. Xia, J.L. Gao, S.Y. Zhang, X.J. Luo, L.Y. Chen, L.Q. Xu, S.L. Tang, Y.W. Du. Opt. Express 22, 1359 (2014).

[15] N. Maccaferri, X. Inchausti, A. García-Martín, J.C. Cuevas, D. Tripathy, A.O. Adeyeye, P. Vavassori. ACS Photonics 2, 1769 (2015).

[16] T.A. Kelf, Y. Sugawara, R.M. Cole, J.J. Baumberg, M.E. Abdelsalam, S. Cintra, S. Mahajan, A.E. Russell, P.N. Bartlett. Phys. Rev. B 74, 245415 (2006). 
[17] A.A. Grunin, N.A. Sapoletova, K.S. Napolskii, A.A. Eliseev, A.A. Fedyanin. J. Appl. Phys. 111, 07A948 (2012).

[18] K. Napolskii, N. Sapoletova, A. Eliseev, G. Tsirlina, A. Rubacheva, E. Ganshina, M. Kuznetsov, M. Ivanov, V. Valdner, E. Mishina, A. van Etteger, Th. Rasing. JMMM 321, 833 (2009).

[19] J.F. Torrado, J.B. González-Díaz, G. Armelles, A. GarcíaMartín, A. Altube, M. López-García, J.F. Galisteo-López, A. Blanco, C. López. Appl. Phys. Lett. 99, 193109 (2011).

[20] E. Melander, E. Östman, J. Keller, J. Schmidt, E.Th. Papaioannou, V. Kapaklis, U.B. Arnalds, B. Caballero, A. GarcíaMartín, J.C. Cuevas, B. Hjörvarsson. Appl. Phys. Lett 101, 063107 (2012).

[21] E.K. Semenova, D.V. Berkov. J. Appl. Phys. 114, 13905 (2013).

[22] R. Zivieri, S. Tacchi, F. Montoncello, L. Giovannini, F. Nizzoli, M. Madami, G. Gubbiotti, G. Carlotti, S. Neusser, G. Duerr, D. Grundler. Phys. Rev. B 85, 012403 (2012).

[23] F. Haering, U. Wiedwald, S. Nothelfer, B. Koslowski, P. Ziemann, L. Lechner, A. Wallucks, K. Lebecki, U. Nowak, J. Gräfe, E. Goering G. Schütz. Nanotechnology 24, 465709 (2013).

[24] T. Meng, J. Laloë, S.N. Holmes, A. Husmann, G.A.C. Jones. Appl. Phys. 106, 033901 (2009).

[25] C.C. Wang, A.O. Adeyeye, N. Singh, Y.S. Huang Y.H. Wu. Phys. Rev. B 72, 174426 (2005).

[26] I.S. Dubitskiy, A.V. Syromyatnikov, N.A. Grigoryeva, A.A. Mistonov, S.V. Grigoriev. arXiv:1509.05201v2 (2015).

[27] A.A. Mistonov, N.A. Grigoryeva, A.V. Chumakova, H. Eckerlebe, N.A. Sapoletova, K.S. Napolskii, A.A. Eliseev, D. Menzel, S.V. Grigoriev. Phys. Rev. B 87, 220408 (2013).

[28] В.Г. Голубев, Д.А. Курдюков, А.Б. Певцов, А.В. Селькин, Е.Б. Шадрин, А.В. Ильинский, Р. Боейинк. ФТП 36, 1122 (2002).

[29] Ю.П. Войнов, Н.Ф. Габитова, В.С. Горелик, Г.А. Емельченко, В.М. Масалов. Неорган. материалы 45, 963 (2009).

[30] R.C. Pennington, G.D' Alessandro, J.J. Baumberg, M. Kaczmarek. Phys. Rev. A 79, 043822 (2009).

[31] F. Le, D.W. Brandl, Y.A. Urzhumov, H. Wang, J. Kundu, N.J. Halas, J. Aizpurua, P. Nordlander. ACS Nano 2, 707 (2008).

[32] S.V. Grigoriev, K.S. Napolskii, N.A. Grigoryeva, A.V. Vasilieva, A.A. Mistonov, D.Yu. Chernyshov, A.V. Petukhov, D.V. Belov, A.A. Eliseev, A.V. Lukashin, Yu.D. Tretyakov, A.S. Sinitskii, H. Eckerlebe. Phys. Rev. B 79, 045123 (2009).

[33] N.A. Grigoryeva, A.A. Mistonov, K.S. Napolskii, N.A. Sapoletova, A.A. Eliseev, W. Bouwman, D.V. Byelov, A.V. Petukhov, D.Yu. Chernyshov, H. Eckerlebe, A.V. Vasilieva, S.V. Grigoriev. Phys. Rev. B 84, 064405 (2011).

[34] А.А. Мистонов, И.С. Шишкин, И.С. Дубицкий, Н.А. Григорьева, Н. Eckerlebe, С.В. Григорьев. ЖЭТФ 147, 976 (2015).

[35] I.S. Shishkin, A.A. Mistonov, I.S. Dubitskiy, N.A. Grigoryeva, D. Menzel, S.V. Grigoriev. Phys. Rev. B 94, 064424 (2016).

[36] A. Sinitskii, V. Abramova, N. Grigorieva, S. Grigoriev, A. Snigirev, D.V. Byelov, A.V. Petukhov. EPL 89, 14002 (2010).

[37] А.К. Самусев, И.С. Синев, К.Б. Самусев, М.В. Рыбин, А.А. Мистонов, Н.А. Григорьева, С.В. Григорьев, А.В. Петухов, Д.В. Белов, Е.Ю. Трофимова, Д.А. Курдюков, В.Г. Голубев, М.Ф. Лимонов. ФТТ 54, 1946 (2012).
[38] M.V. Rybin, I.S. Sinev, A.K. Samusev, K.B. Samusev, E.Y. Trofimova, D.A. Kurdyukov, V.G. Golubev, M.F. Limonov. Phys. Rev. B 87, 125131 (2013).

[39] А.К. Самусев, К.Б. Самусев, М.В. Рыбин, М.Ф. Лимонов, Е.Ю. Трофимова, Д.А. Курдюков, В.Г. Голубев. ФТТ 53, 993 (2011).

[40] M.V. Rybin, K.B. Samusev, S.Y. Lukashenko, Y.S. Kivshar, M.F. Limonov. Scientific Reports 6, 30773 (2016).

[41] E. Armstrong, M. Osiak, H. Geaney, C. Glynn, C. O’Dwyer. CrystEngComm 16, 10804 (2014).

[42] A. Balestreri, L.C. Andreani, M. Agio. Phys. Rev. E 74, 036603 (2006).

[43] X. Yu, Y.J. Lee, R. Furstenberg, J.O. White, P.V. Braun. Adv. Mater. 19, 1689 (2007).

[44] N. Sapoletova, T. Makarevich, K. Napolskii, E. Mishina, A. Eliseev, A. Etteger, T. Rasing, G. Tsirlina. Phys. Chem. Chem. Phys. 12, 15414 (2010).

[45] J.W. Goodwin, J. Hearn, C.C. Ho, R.H. Ottewill. Colloid Polymer Science 252, 464 (1974).

[46] K.S. Napolskii, A. Sinitskii, S.V. Grigoriev, N.A. Grigorieva, H. Eckerlebe, A.A. Eliseev, A.V. Lukashin, Y.D. Tretyakov. Physica B: Condensed Matter 397, 23 (2007).

[47] Н.А. Саполетова, К.С. Мартынова, К.С. Напольский, А.А. Елисеев, А.В. Лукашин, И.В. Колесник, Д.И. Петухов, С.Е. Кушнир, А.В. Васильева, С.В. Григорьев, Н.А. Григорьева, А.А. Мистонов, Д.В. Белов, Ю.Д. Третьяков. ФТТ 53, 1064 (2011).

[48] A.V. Chumakova, G.A. Valkovskiy, A.A. Mistonov, V.A. Dyadkin, N.A. Grigoryeva, N.A. Sapoletova, K.S. Napolskii, A.A. Eliseev, A.V. Petukhov, S.V. Grigoriev. Phys. Rev. B 90, 144103 (2014).

[49] M. Borsboom, W. Bras, I. Cerjak, D. Detollenaere, D. Glastra van Loon, P. Goedtkindt, M. Konijnenburg, P. Lassing, Y.K. Levine, B. Munneke, M. Oversluizen, R. van Tol, E. Vlieg. J. Synchrotron Rad. 5, 518 (1998).

[50] A. Snigirev, V. Kohn, I. Snigireva, B. Lengeler. Nature 384, 49 (1996).

[51] А.А. Елисеев, Д.Ф. Горожанкин, К.С. Напольский, А.В. Петухов, Н.А. Саполетова, А.В. Васильева, Н.А. Григорьева, А.А. Мистонов, Д.В. Белов, В.Г. Бауман, К.О. Квашнина, Д.Ю. Чернышов, А.А. Босак, С.В. Григорьев. Письма в ЖЭТФ 90, 297 (2009).

[52] P. Huber, O. Bunk, U. Pietsch, M. Textor, T. Geue. J. Phys. Chem. B 114, 12473 (2010).

[53] R.P.A. Dullens, A.V. Petukhov. Europhys. Lett. 77, 58003 (2007).

[54] J.H. Hubbell, W.J. Veigele, E.A. Briggs, R.T. Brown, D.T. Cromer, R.J. Howerton. J. Phys. Chem. Ref. Data 4, 471 (1975).

[55] R. Lazzari. J. Appl. Crystallogr 35, 406 (2002).

[56] M. de Graef, M.E. McHenry. Structure of materials: An introduction to crystallography, diffraction, and symmetry. Cambridge University Press, N. Y. (2012). 739 c.

[57] S.K. Sinha, E.B. Sirota, S. Garoff, H.B. Stanley. Phys. Rev. B 38, 2297 (1998).

[58] А.А. Мистонов. Канд. дисс. Санкт-Петербург (2013).

[59] K. Busch, S. John. Phys. Rev. E 58, 3896 (1998).

[60] И.С. Шишкин, А.А. Мистонов, Н.А. Григорьева, D. Menzel, С.В. Григорьев. Поверхность. Рентгеновские, синхротронные и нейтронные исследования 2, 3 (2016).

[61] A. Guinier. X-ray diffraction in crystals, imperfect crystals, and amorphous bodies. Dover, N. Y. (1994). $378 \mathrm{c}$. 